\title{
Power Flow in a Multi-Frequency HVac and HVdc System: Formulation, Solution, and Validation
}

\author{
Quan Nguyen, Student Member, IEEE, Grazia Todeschini, Senior Member, IEEE, and Surya Santoso, Fellow, IEEE
}

\begin{abstract}
This paper proposes a novel power flow formulation and solution algorithm for a generalized large-scale interconnected transmission system encompassing multi-frequency HVac and HVdc grids having arbitrary numbers of buses, topologies, and operating frequencies. Back-to-back and ac/dc voltage-source converters are employed to interconnect and control the voltage and power interchange between two power grids operating at different frequencies. The power flow formulation is based on a steady-state model of back-to-back and ac/dc converters operated in centralized and distributed droop control strategies. Each power grid is represented by a set of nonlinear power balance equations. These equations are solved simultaneously using a unified power flow algorithm, taking into account generator and converter limits. It is shown that the solution convergence is achieved rapidly despite the system size, topology, and converter control strategies. The efficacy and accuracy of the proposed steady-state solution algorithm are demonstrated by comparing the numerical solution to the one obtained by time-domain electromagnetic models of multi-frequency HVac and HVdc transmission systems with fully controllable backto-back and ac/dc converters. The results obtained by using the proposed algorithm and the time-domain simulation are practically identical.
\end{abstract}

Index Terms-Back-to-back converter, Droop control, Low frequency transmission, Multi-frequency systems, Power flow.

\section{INTRODUCTION}

$\mathbf{I}$ $\mathrm{N}$ past decades, the transmission of bulk electric power from remote generation stations to load centers has been using high-voltage alternating current (HVac) and direct current $(\mathrm{HVdc})$ transmission systems. After years of design and operating experience, it is well understood that each system possesses inherent advantages and disadvantages. HVdc systems virtually have unrestricted point-to-point long-distance transmission capacity, the ability to interconnect ac systems with different frequencies, reduced conductor loss, lower insulation level, and narrower right of way. On the other hand, HVac systems offer flexible multi-point interconnection capability as well as reliable system protection devices and techniques [1]-[5].

Considering the limitations of both HVac and HVdc sytems, low frequency HVac (LF-HVac) has been recently proposed as an alternate solution. LF-HVac systems combine the advantages of the two existing configurations, such as high power-carrying capability over long distance, the use of meshconnected (multi-terminal) networks, and straightforward ac protection system [6]-[9]. In addition, a significant reduction in reactance at low frequency benefits LF-HVac transmission

The authors are with the Department of Electrical and Computer Engineering, University of Texas at Austin (e-mail: quan.nguyenhuy @utexas.edu; ssantoso@mail.utexas.edu) and with the College of Engineering, Swansea University (email: grazia.todeschini@swansea.ac.uk). systems in terms of superior voltage profile due to lower voltage drop, and improved system stability [10]-[12]. In [13] and [14], the possibility of implementing $16.7 \mathrm{~Hz} \mathrm{LF-HVac}$ transmission for practical offshore wind farm applications in Europe is investigated.

These theoretical advantages suggest the feasibility of multifrequency HVac power systems, in which short and medium lines are operated at 50 or $60 \mathrm{~Hz}$, while longer lines are operated at lower and variable frequencies. Similar to $\mathrm{HVdc}$ systems, multi-frequency $\mathrm{HVac}$ systems employ converters to establish a connection to other grids. Possible converter topologies include cyclo converters [8], [9] and back-to-back (BTB) converters. The latter has the advantages of independent active and reactive power control, low harmonic content of the output waveforms, and the ability to obtain any desired operating frequencies [15]-[17]. However, further break-even point analysis is necessary to determine the suitable and favorable transmission system operating conditions and requirements that are more economically attractive to the proposed multifrequency HVac power systems.

For system planning and steady-state operation purposes, a power flow solution is needed for a multi-frequency power system where LF-HVac and HVdc grids may be connected to standard 50- or $60-\mathrm{Hz}$ HVac grids through BTB or ac/dc voltage-source converters (VSC). The power flow solution can be used to determine system losses, the optimal operating frequency of a given LF-HVac grid, and initial conditions for stability studies. To the best knowledge of the authors, little research has been done to solve power flow in multi-frequency power systems. A simplified method that does not include the BTB converter systems was proposed in [18]. The power flow solution presented in this paper takes into account the model and power control capability of BTB converters.

The ac/dc converter model is included in the power flow solution for HVac and HVdc systems, where either unified or sequential approaches can be applied [19]-[22]. The unified algorithm remodels the entire system, including converters by a set of non-linear equations, and then solves them concurrently. In contrast, the sequential algorithm inherits the simplicity of the existing ac power-flow scheme and solves for the power flow of each grid separately. Therefore, the sequential approach requires additional outer loops to make the power flow at converter stations converge.

Single-stage ac/dc converters between HVac and HVdc grids are operated either in rectifier or inverter mode, while these two modes operate simultaneously for BTB converters in multi-frequency HVac systems. In this paper, both practical centralized and distributed control strategies for the ac/dc 


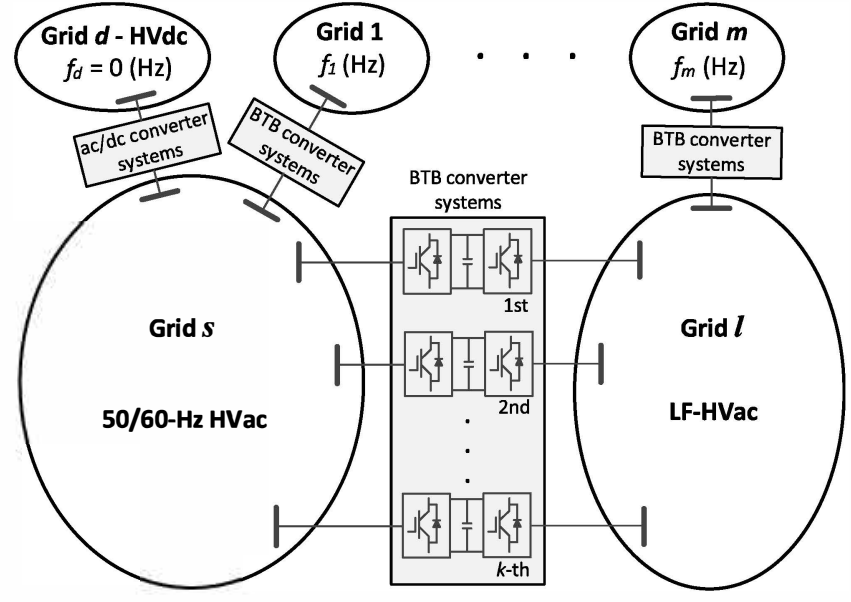

Fig. 1. Generalized multi-frequency power systems. Each LF-HVac and HVdc system is interconnected to an HVac grid through BTB and ac/dc converters, respectively.

converters are considered and implemented. The former results in a HVdc grid with constant voltage at the slack bus, and the converter connected to this slack bus accounts for system losses. The latter results in a HVdc grid where all converters participate in voltage and power control. The participation of each converter is dictated its pre-defined droop characteristic.

The contributions of this paper include: 1) a description of novel operation with the centralized control strategy and power flow model for BTB converters in multi-frequency HVac systems, and 2) a generalized power flow formulation and algorithm for multi-frequency HVac and HVdc power systems based on the unified approach. The proposed approach is applicable to a large interconnected power system, as shown in Fig. 1, which contain arbitrary numbers of converters, ac/dc grids, and operating frequencies.

In the remainder of this paper, Section II introduces the operating modes and coordination of BTB converters in multifrequency HVac systems. Section III formulates sets of nonlinear equations representing the power balance in HVac, LFHVac, and HVdc grids as well as converter stations. The power flow equations are solved simultaneously by an efficient algorithm described in Section IV. In Section V, the use of the algorithm is exemplified in a case study. The analytical solution is compared to the steady-state simulation result obtained from the system model developed in PSCAD/EMTDC timedomain environment.

\section{BTB CONVERTERS IN MUlTi-FreQUency HVAC POWER SYSTEMS}

This section focuses on the modeling of BTB converters in multi-frequency HVac systems such as the one shown in Fig. 1. Without loss of generality, only $k$ BTB converters that connect HVac grid $s$ and LF-HVac grid $l$ are presented. Section II.A describes a typical structure of BTB converter stations and their equivalent model. Section II.B proposes the converter operating modes and coordination between the two sides of each BTB converter in general multi-frequency HVac systems.

\section{A. Steady-State Model of BTB Converter Stations}

In multi-frequency HVac power systems, each BTB converter station consists of two voltage-source converters (VSC) denoted as $\mathrm{VSC}_{1}$ and $\mathrm{VSC}_{2}$, as shown in Fig. 2. $\mathrm{VSC}_{1}$ and $\mathrm{VSC}_{2}$ have identical structures and electrical components. These two converters share a common dc-link capacitor, which acts as an intermediate energy storage component and allows decoupled operation of converters $\mathrm{VSC}_{1}$ and $\mathrm{VSC}_{2}$. Similar to the physical structure of VSC converter stations in HVdc systems, each side of the BTB converter station in multi-frequency HVac systems consists of a transformer, shunt capacitor, a phase reactor, and switching valves. Fig. 3 shows the single-line equivalent power-flow model of a converter station in multi-frequency HVac systems. Each VSC converter can be thought of as a synchronous machine without inertia. Assuming converter voltages $\bar{V}_{c 1}$ and $\bar{V}_{c 2}$ contain no harmonic, each VSC converter is represented as a controllable voltage source behind an impedance [21], [23], [24]. The impedances $\bar{Z}_{T 1}$ and $\bar{Z}_{T 2}, \bar{Z}_{f 1}$ and $\bar{Z}_{f 2}$, and $\bar{Z}_{c 1}$ and $\bar{Z}_{c 2}$ represent the transformer leakage impedances, shunt capacitor impedances, and the phase reactor impedances, respectively, at both side of the BTB converter. The parameters in Fig. 2 and Fig. 3 are defined as follows: $\bar{V}_{s, i}, \bar{V}_{l, i} \quad$ voltage at the $i^{t h}$ bus in HVac grid $s$ and LF-HVac grid $l$;

$P_{s, i}^{c o n v}, Q_{s, i}^{c o n v}$ active and reactive power flowing from HVac grid $s$ toward $\mathrm{VSC}_{1}$;

$P_{l, i}^{c o n v}, Q_{l, i}^{c o n v}$ active and reactive power flowing from $\mathrm{VSC}_{2}$ toward LF-HVac grid $l$;

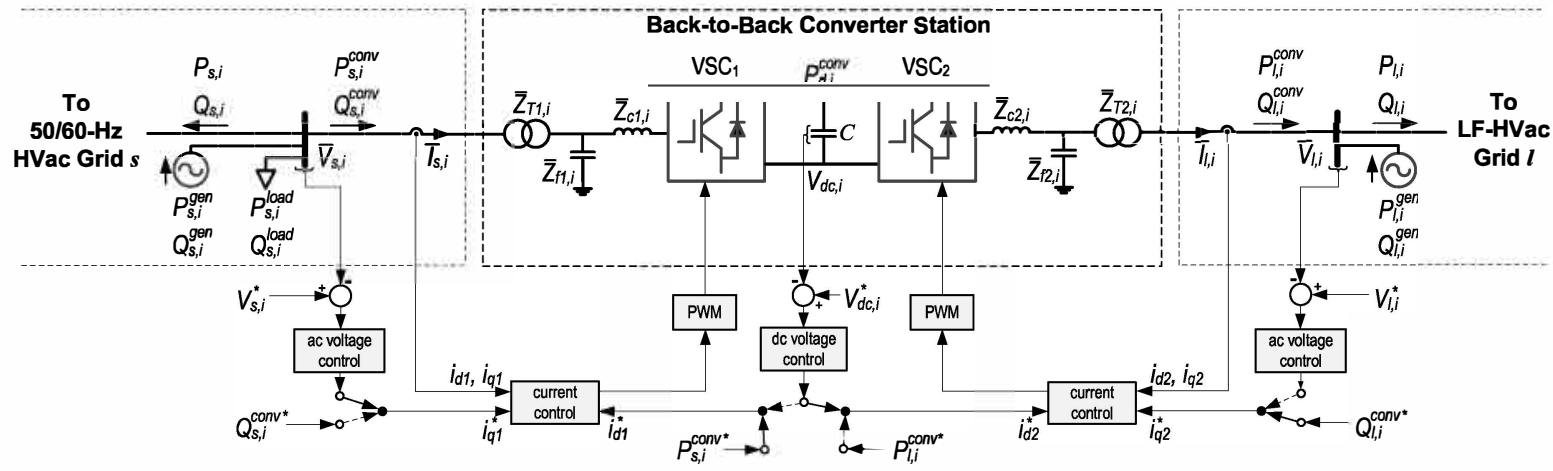

Fig. 2. A BTB converter is used to connect an LF-HVac grid to a 50/60-Hz HVac grid: the system configuration, the interface between the two grids, and the main control blocks. 


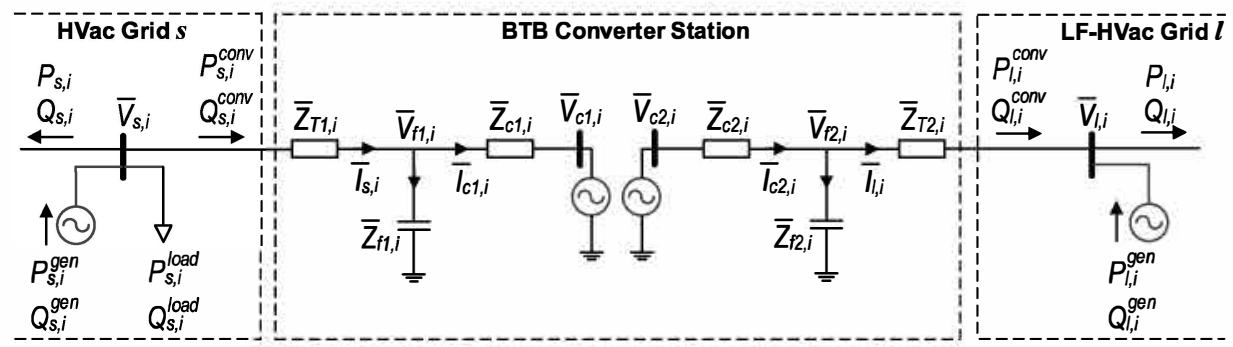

Fig. 3. Single-line equivalent power-flow model of the BTB converter station shown in Fig. 2.

\begin{tabular}{|c|c|}
\hline$P_{d, i}^{c o n v}$ & $\begin{array}{l}\text { active power flowing from } \mathrm{VSC}_{1} \text { to } \\
\mathrm{VSC}_{2} \text {; }\end{array}$ \\
\hline$P_{s, i}, Q_{s, i}$ & $\begin{array}{l}\text { active and reactive power injected into } \\
\text { HVac grid } s \text { at the } i^{t h} \text { bus; }\end{array}$ \\
\hline$P_{l, i}, Q_{l, i}$ & $\begin{array}{l}\text { active and reactive power injected into } \\
\text { LF-HVac grid } l \text { at the } i^{\text {th }} \text { bus; }\end{array}$ \\
\hline$P_{s, i}^{g e n}, Q_{s, i}^{g e n}$ & $\begin{array}{l}\text { active and reactive power generated at } \\
\text { the } i^{\text {th }} \text { bus in HVac grid } s \text {; }\end{array}$ \\
\hline$P_{l, i}^{g e n}, Q_{l, i}^{g e n}$ & $\begin{array}{l}\text { active and reactive power generated at } \\
\text { the } i^{\text {th }} \text { bus in LF-HVac grid } l \text {; }\end{array}$ \\
\hline$P_{s, i}^{l o a d}, Q_{s, i}^{l o a d}$ & $\begin{array}{l}\text { active and reactive power consumed } \\
\text { the } i^{\text {th }} \text { bus in HVac grid } s \text {. }\end{array}$ \\
\hline
\end{tabular}

If the $i^{t h}$ bus in either HVac grid $s$ or LF-HVac grid $l$ is not connected to any converters, the corresponding parameters $P_{s, i}^{c o n v}$ and $Q_{s, i}^{c o n v}$ or $P_{l, i}^{c o n v}$ and $Q_{l, i}^{c o n v}$, respectively, are set to zero. In addition, loads are assumed to be located only in HVac grid $s$; LF-HVac grid $l$ does not serve any loads.

\section{B. Operation Modes and Coordination of BTB Converters with Centralized Control in Multi-Frequency HVac Systems}

As mentioned above, $\mathrm{VSC}_{1}$ and $\mathrm{VSC}_{2}$ are decoupled by controlling the voltage of the dc-link capacitor. The independent control of active and reactive power injected or withdrawn from the ac grid at each side is achieved by regulating the $d$ - and $q$-axis components of the converter current in the synchronously rotating reference frame [15], [25]. By controlling the current component $i_{d}, \mathrm{VSC}_{1}$ and $\mathrm{VSC}_{2}$ regulate the active power $P_{s, i}^{c o n v}$ and $P_{l, i}^{c o n v}$ injected or withdrawn from HVac grid $s$ and LF-HVac grid $l$, respectively. Alternatively, the active power control target can be changed to regulate the dc-link voltage $V_{d c, i}$, as shown in Fig. 2. On the other hand, controlling the current component $i_{q}$ allows $\mathrm{VSC}_{1}$ and $\mathrm{VSC}_{2}$ to regulate reactive power $Q_{s, i}^{\text {conv }}$ and $Q_{l, i}^{\text {conv }}$ injected or withdrawn from HVac grid $s$ and LF-HVac grid $l$, respectively. Alternatively, the values of $Q_{s, i}^{c o n v}$ and/or $Q_{l, i}^{\text {conv }}$ can be adjusted so that the voltage magnitude $V_{s, i}$ or $V_{l, i}$ of the associated bus in HVac grid $s$ or LF-HVac grid $l$ is kept constant.

When $k$ BTB converters are used as power flow controllers between HVac grid $s$ and LF-HVac grid $l$, as shown in Fig. 1 , the following operating modes are proposed to regulate the power, dc-link voltage, and/or ac voltage magnitude of the ac bus at each side of $k$-1 BTB converters:

- Converter VSC $\mathrm{VS}_{1}$, which is connected to HVac grid $s$, is set to regulate active and reactive power (PQ mode) or active power and voltage magnitude at the $i^{\text {th }}$ bus in HVac grid $s$ (PV mode). This means that $P_{s, i}^{c o n v}$ and $Q_{s, i}^{c o n v}$ in PQ mode or $P_{s, i}^{c o n v}$ and $V_{s, i}$ in $\mathrm{PV}$ mode are the input for the power flow analysis.

- Converter $\mathrm{VSC}_{2}$, which is connected to LF-HVac grid $l$, is set to regulate the dc-link voltage and to control either reactive power $\left(\mathrm{QV}_{\mathrm{dc}}\right.$ mode $)$ or the terminal voltage magnitude $\left(\mathrm{VV}_{\mathrm{dc}}\right.$ mode). This implies that either $Q_{l, i}^{c o n v}$ in $\mathrm{QV}_{\mathrm{dc}}$ mode or $V_{l, i}$ in $\mathrm{VV}_{\mathrm{dc}}$ mode is a known quantity while $P_{l, i}^{c o n v}$ is unknown and needs to be determined.

This approach does not apply to one particular converter, which varies the reactive power $Q_{l, s l}^{c o n v}$ at the $\mathrm{VSC}_{2}$ side to control the voltage magnitude $V_{l, s l}$ at the slack bus of LF-HVac grid $l$. Therefore, $Q_{l, s l}^{c o n v}$ is unknown prior to solving the power flow. The active power $P_{l, s l}^{c o n v}$ flowing toward $\mathrm{VSC}_{2}$ from the slack bus is also unknown since it depends on the losses in LF-HVac grid $l$. Since the phase angle reference is lost due to the intermediate dc stage in the ac/dc/ac conversion, the phase angle of the slack bus in LF-HVac grid $l$ is considered to be zero. These properties are consistent with the concept of the slack bus in conventional HVac grids. At the $\mathrm{VSC}_{1}$ side of the converter connected to the slack bus in LF-HVac grid $l$, only the reactive power $Q_{s, s l}^{c o n v}$ is controlled. The active power $P_{s, s l}^{c o n v}$ is unknown since it depends on the unknown active power $P_{l, s l}^{c o n v}$, on the Joule losses due to the real parts of $Z_{T 1}$, $Z_{c 1}, Z_{T 2}$, and $Z_{c 2}$, and on the switching losses in $\mathrm{VSC}_{1}$ and $\mathrm{VSC}_{2}$. Note that the ac bus connected to the $\mathrm{VSC}_{1}$ side of this converter does not need to be the slack bus of HVac grid $s$.

Table I summarizes the converter type, operating modes, and control parameters (given and unknown). This operating principle can be applied to power systems with unlimited numbers of ac grids and operating frequencies, as shown in Fig 1. Each pair of grids is connected by means of a group of converters, and each grid has an independent slack bus.

TABLE I

BTB CONVERTER OPERATING MOdes AND DATA Classification fOR POWER FlOW ALGORITHM.

\begin{tabular}{c|c|cc}
\hline \multicolumn{5}{|c}{$\mathrm{VSC}_{1}$ at the HVac grid side } \\
\hline Converter type & Control modes & Given & Unknown \\
\hline slack & $\mathrm{Q}$ & $Q_{s}^{\text {conv }}$ & $V_{s}, \theta_{s}, P_{s}^{\text {conv }}$ \\
\hline \multirow{2}{*}{ non-slack } & $\mathrm{PQ}$ & $P_{s}^{\text {conv }}, Q_{s}^{\text {conv }}$ & $V_{s}, \theta_{s}$ \\
& $\mathrm{PV}$ & $V_{s}, P_{s}^{\text {conv }}$ & $\theta_{s}, Q_{s}^{\text {conv }}$ \\
\hline \hline \multicolumn{5}{|c}{$\mathrm{VSC}_{2}$ at the $\mathrm{LF}-\mathrm{HVac}$ grid side } \\
\hline Converter type & Control modes & Given & Unknown \\
\hline slack & $\mathrm{VV}_{\mathrm{dc}}$ & $V_{l}, \theta_{l}$ & $P_{l}^{\text {conv }}, Q_{l}^{\text {conv }}$ \\
\hline \multirow{2}{*}{ non-slack } & $\mathrm{QV}_{\mathrm{dc}}$ & $Q_{l}^{\text {conv }}$ & $V_{l}, \theta_{l}, P_{l}^{\text {conv }}$ \\
& $\mathrm{VV}_{\mathrm{dc}}$ & $V_{l}$ & $\theta_{l}, P_{l}^{\text {conv }}, Q_{l}^{\text {conv }}$ \\
\hline
\end{tabular}




\section{POWER FLOW FORMULATION}

This section addresses the power flow model of a general multi-frequency power system such as the one shown in Fig. 1. The model of HVac grid $s$, LF-HVac grid $l$, and the BTB converters in multi-frequency HVac systems, illustrated in Fig. 3, is derived. The model of ac/dc VSC converters with a generalized voltage-power $(V-P)$ droop control and the model of HVdc grid $d$ are directly inherited from [19]-[22], [26], [27]. The following notations will be used to group different sets of buses in the power flow equations: $\mathcal{N}_{*} \quad$ the set of all buses in a grid;

$\mathcal{N}_{*}^{\prime} \quad$ the set of buses except the slack bus;

$\mathcal{L}_{*} \quad$ the set of non-voltage-controlled buses;

$\mathcal{C}_{*} \quad$ the set of buses connected to converters;

$\mathcal{G}_{*} \quad$ the set of generator buses;

$\mathcal{V}_{*} \quad$ the set of buses connected to converters operate in voltage-controlled mode;

where the subscript $*$ is either $s, l, d, c$ corresponding to the HVac grid, LF-HVac grid, HVdc grid, or converters, respectively.

\section{A. HVac Grid}

The set of power balance equations $\boldsymbol{g}_{s}^{P Q}$ of HVac grid $s$, representing the active power balance at non-slack buses and the reactive power balance at non-voltage-controlled buses, is given by:

$$
\begin{aligned}
& g_{s, i}^{P}\left(\boldsymbol{X}_{\boldsymbol{s}}\right)=P_{s, i}-\left(P_{s, i}^{g e n}-P_{s, i}^{\text {load }}-P_{s, i}^{\text {conv }}\right)=0, \forall i \in \mathcal{N}_{s}^{\prime}, \\
& g_{s, i}^{Q}\left(\boldsymbol{X}_{\boldsymbol{s}}\right)=Q_{s, i}-\left(Q_{s, i}^{\text {gen }}-Q_{s, i}^{\text {load }}-Q_{s, i}^{\text {conv }}\right)=0, \forall i \in \mathcal{L}_{s},
\end{aligned}
$$

where $\boldsymbol{X}_{\boldsymbol{s}}=\left[\boldsymbol{\theta}_{\boldsymbol{s}}, \boldsymbol{V}_{\boldsymbol{s}}, \boldsymbol{P}_{\boldsymbol{s}}^{\boldsymbol{c o n v}}\right]$ is a vector containing the phase angles of non-slack buses, the voltage magnitudes of nonvoltage-controlled buses, and the unknown active power flowing toward the converter connected to the slack bus in LFHVac grid $l$ and all converters connected to HVdc grid $d$, as discussed in Section III.E. The power $P_{s, i}$ and $Q_{s, i}$ injected into HVac grid $s$ at the $i^{t h}$ bus in (1) are as follows:

$$
\begin{aligned}
& P_{s, i}=V_{s, i} \sum_{k \in \mathcal{N}_{s}} V_{s, k}\left[G_{s, i k} \cos \left(\theta_{s, i k}\right)+B_{s, i k} \sin \left(\theta_{s, i k}\right)\right], \\
& Q_{s, i}=V_{s, i} \sum_{k \in \mathcal{N}_{s}} V_{s, k}\left[G_{s, i k} \sin \left(\theta_{s, i k}\right)-B_{s, i k} \cos \left(\theta_{s, i k}\right)\right],
\end{aligned}
$$

where $\theta_{s, i k}=\theta_{s, i}-\theta_{s, k}$ and $G_{s, i k}+j B_{s, i k}$ is the admittance of the line between the $i^{\text {th }}$ and $k^{\text {th }}$ buses.

\section{B. LF-HVac Grid}

As discussed in Section II.B, not only voltage magnitudes $V_{l}$ of non-voltage-controlled buses and phase angles $\theta_{l}$ of nonslack buses but also active power $P_{l}^{\text {conv }}$ injected into LFHVac grid $l$ from converters $\mathrm{VSC}_{2}$ are unknown. The set of power balance equations $\boldsymbol{g}_{l}^{P Q}$ of LF-HVac grid $l$ describes the active power balance at all buses and the reactive power balance at non-voltage-controlled buses:

$$
\begin{aligned}
& g_{l, i}^{P}\left(\boldsymbol{X}_{\boldsymbol{l}}\right)=P_{l, i}-\left(P_{l, i}^{g e n}+P_{l, i}^{c o n v}\right)=0, \forall i \in \mathcal{N}_{l}, \\
& g_{l, i}^{Q}\left(\boldsymbol{X}_{\boldsymbol{l}}\right)=Q_{l, i}-\left(Q_{l, i}^{g e n}+Q_{l, i}^{c o n v}\right)=0, \forall i \in \mathcal{L}_{l},
\end{aligned}
$$

where $\boldsymbol{X}_{\boldsymbol{l}}=\left[\boldsymbol{\theta}_{\boldsymbol{l}}, \boldsymbol{V}_{\boldsymbol{l}}, \boldsymbol{P}_{\boldsymbol{l}}^{\boldsymbol{c o n} \boldsymbol{v}}\right]$. The power $P_{l, i}$ and $Q_{l, i}$ injected into LF-HVac grid $l$ at the $i^{\text {th }}$ bus in (3) are obtained with an expression similar to (2).

\section{BTB Converters between HVac and LF-HVac Grids}

With the power and current directions shown in Fig. 3, the currents $I_{s, i}$ withdrawn from HVac grid $s$ and $I_{l, i}$ injected into LF-HVac grid $l$ as well as the voltages at the shunt capacitor terminals are determined as follows:

$$
\begin{gathered}
\bar{I}_{s, i}=\frac{P_{s, i}^{c o n v}-j Q_{s, i}^{c o n v}}{\bar{V}_{s, i}^{*}} ; \bar{V}_{f 1, i}=\bar{V}_{s, i}-\bar{I}_{s, i} \bar{Z}_{T 1, i}, \forall i \in \mathcal{C}_{s}, \\
\bar{I}_{l, i}=\frac{P_{l, i}^{c o n v}-j Q_{l, i}^{c o n v}}{\bar{V}_{l, i}^{*}} ; \bar{V}_{f 2, i}=\bar{V}_{l, i}+\bar{I}_{l, i} \bar{Z}_{T 2, i}, \forall i \in \mathcal{C}_{l},
\end{gathered}
$$

Converter currents $\bar{I}_{c 1, i}$ and $\bar{I}_{c 2, i}$ as well as voltages $\bar{V}_{c 1, i}$ and $\bar{V}_{c 2, i}$ at each side of the BTB converter are determined as follows:

$$
\begin{aligned}
& \bar{I}_{c 1, i}=\bar{I}_{s, i}-\bar{V}_{f 1, i} / \bar{Z}_{f 1, i} ; \bar{V}_{c 1, i}=\bar{V}_{f 1, i}-\bar{I}_{c 1, i} \bar{Z}_{c 1, i}, \forall i \in \mathcal{C}_{s}, \\
& \bar{I}_{c 2, i}=\bar{I}_{l, i}+\bar{V}_{f 2, i} / \bar{Z}_{f 2, i} ; \bar{V}_{c 2, i}=\bar{V}_{f 2, i}+\bar{I}_{c 2, i} \bar{Z}_{c 2, i}, \forall i \in \mathcal{C}_{l} .
\end{aligned}
$$

The Joule and switching losses $P_{J 1, i}, P_{s w 1, i}, P_{J 2, i}$, and $P_{s w 2, i}$ at each side of the BTB converter are calculated as follows [21], [22]:

$$
\begin{aligned}
P_{J 1, i} & =I_{s, i}^{2} R_{T 1, i}+I_{c 1, i}^{2} R_{c 1, i}, \forall i \in \mathcal{C}_{s} ; \\
P_{s w 1, i} & =a_{0}+a_{1} I_{c 1, i}+a_{2} I_{c 1, i}^{2}, \forall i \in \mathcal{C}_{s} ; \\
P_{J 2, i} & =I_{l, i}^{2} R_{T 2, i}+I_{c 2, i}^{2} R_{c 2, i}, \forall i \in \mathcal{C}_{l} ; \\
P_{s w 2, i} & =a_{0}+a_{1} I_{c 2, i}+a_{2} I_{c 2, i}^{2}, \forall i \in \mathcal{C}_{l},
\end{aligned}
$$

where $R_{T 1, i}, R_{T 2, i}, R_{c 1, i}$, and $R_{c 2, i}$ are the winding resistances of the transformers and phase reactors while $a_{0}, a_{1}$, and $a_{2}$ are given coefficients. For the converter connected to the slack bus of LF-HVac grid $l$, it can be seen from (4)-(6) and Table I that $P_{J 1, i}$ and $P_{s w 1, i}$ are functions of $P_{s, i}^{c o n v}$ and $V_{s, i}$ while $P_{J 2, i}$ and $P_{s w 2, i}$ are functions of only $P_{l, i}^{c o n v}$. For the other converters, $P_{J 1, i}$ and $P_{s w 1, i}$ are functions of $V_{s, i}$ while $P_{J 2, i}$ and $P_{s w 2, i}$ are functions of both $V_{l, i}$ and $P_{l, i}^{c o n v}$.

The power balance equation $g_{c l, i}^{P}$ at the $i^{\text {th }}$ BTB converter connecting HVac grid $s$ and LF-HVac grid $l$ is obtained from the relationship between $P_{s, i}^{c o n v}, P_{l, i}^{c o n v}$, and the Joule and switching losses:

$$
\begin{gathered}
g_{c l, i}^{P}\left(V_{s, i}, V_{l, i}, P_{s, i}^{c o n v}, P_{l, i}^{c o n v}\right)=P_{l, i}^{c o n v}+P_{J 2, i}+P_{s w 2, i} \\
+P_{J 1, i}+P_{s w 1, i}-P_{s, i}^{c o n v}=0 .
\end{gathered}
$$

\section{HVdc Grid}

The set of power balance equations $\boldsymbol{g}_{d}^{P}$ of HVdc grid $d$ represents the active power balance at all buses:

$$
g_{d, i}^{P}\left(\boldsymbol{X}_{\boldsymbol{d}}\right)=P_{d, i}-P_{d, i}^{c o n v}=0, \forall i \in \mathcal{N}_{d},
$$

where $\boldsymbol{X}_{\boldsymbol{d}}=\left[\boldsymbol{V}_{\boldsymbol{d}}, \boldsymbol{P}_{\boldsymbol{d}}^{\text {conv }}\right]$ is a vector containing dc bus voltages and unknown active power flowing into HVdc grid $d$ from the associated converters. The active power $P_{d, i}$ injected into HVdc grid $d$ at the $i^{\text {th }}$ bus is given by:

$$
P_{d, i}=k_{t y p e} V_{d, i} \sum_{k \in \mathcal{N}_{d}} V_{d, k} Y_{d, i k},
$$

where $k_{\text {type }}$ is a coefficient depending on the type of $\mathrm{HVdc}$ grid $\left(k_{\text {type }}=1\right.$ for monopolar $\mathrm{HVdc}$ and $k_{\text {type }}=2$ for bipolar HVdc) while $Y_{d, i k}$ is the admittance of the line between the $i^{\text {th }}$ and $k^{\text {th }}$ buses. 


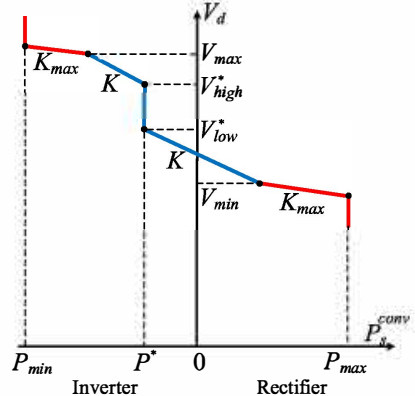

(a)

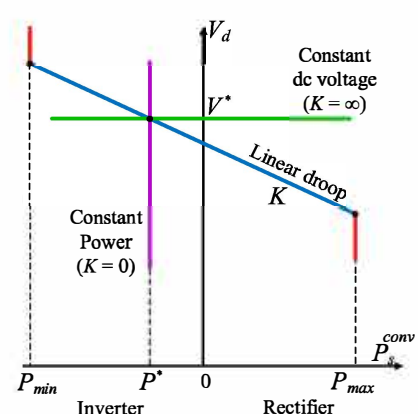

(b)
Fig. 4. a) $V-P$ droop control with a power dead-band and voltage limits, b) Linear $V-P$ droop control. The parameters $V_{\max }, V_{\min }, P_{\max }, P_{\min }$, $V_{\text {low }}^{*}, V_{\text {high }}^{*}, P^{*}$, and $V^{*}$ are usually chosen based on the power flow results with the centralized control.

\section{E. VSC Converters between HVac and HVdc Grids}

Each converter station connecting HVac grid $s$ and HVdc grid $d$ consists of only a single-stage ac/dc converter, which is similar to $\mathrm{VSC}_{1}$ in Fig. 2 . Therefore, the equation $g_{c d, i}^{P}$ representing the active power balance at the $i^{\text {th }}$ converter is given as follows [19], [21], [22]:

$g_{c d, i}^{P}\left(V_{s, i}, P_{d, i}^{c o n v}, P_{s, i}^{c o n v}\right)=P_{d, i}^{c o n v}+P_{J 1, i}+P_{s w 1, i}-P_{s, i}^{c o n v}=0$.

In (10), the active power $\boldsymbol{P}_{\boldsymbol{s}}^{\text {conv }}$ and $\boldsymbol{P}_{\boldsymbol{d}}^{\text {conv }}$ at two sides of the converters that connect HVac grid $s$ and $\mathrm{HVdc}$ grid $d$ depend on the control scheme of those converters. Centralized control, characterized by a constant dc voltage at the slack bus and constant injected active power at the other dc buses, share similarities with HVac grid $s$ and LF-HVac grid $l$ as discussed above. Although this centralized control strategy can be directly incorporated into ac power flow algorithm [19]-[22], in practice, it may become ineffective following a failure of the converter connected to the slack bus in $\mathrm{HVdc}$ grid $d$. To improve the robustness of the formulation, this paper also considers and implements distributed linear and nonlinear droop controls [26]-[28]. The most generalized droop control is the $V-P$ droop, in which the set point of converter power $P_{s}^{c o n v}$ varies according to the local dc voltage in a nonlinear curve with dead-bands and voltage limits, as shown in Fig. 4(a). When $V_{\text {low }}^{*}=V_{\text {high }}^{*}$ and droop coefficients $K=K_{\text {max }}$, the nonlinear characteristic becomes linear, as shown in Fig. 4(b). If the droop coefficients are infinity or zero, the droop control becomes constant dc voltage or constant active power control, respectively, as in the centralized control strategy.

In a power flow formulation with the generalized droop control characteristic, dc voltages $V_{\boldsymbol{d}}$ and both converter power $\boldsymbol{P}_{\boldsymbol{s}}^{c o n v}$, and $\boldsymbol{P}_{\boldsymbol{d}}^{\boldsymbol{c o n v}}$ at two sides of the VSC converters are unknown. Existing $V-P$ curves in the literature such as [26]-[28] directly consider $\boldsymbol{P}_{\boldsymbol{d}}^{\text {conv }}$ as a function of $\boldsymbol{V}_{\boldsymbol{d}}$ by assuming lossless converters. However, the power control is implemented at the ac side, as shown in Fig. 2, and $\boldsymbol{P}_{d}^{\text {conv }}$ and $\boldsymbol{P}_{\boldsymbol{s}}^{\boldsymbol{c o n v} v}$ are not equal to each other due to converter losses. Therefore, this paper considers the droop characteristic for $P_{s}^{c o n v}$ and $V_{d}$ as follows:

$$
g_{\text {droop }, i}^{P}\left(V_{d, i}, P_{s, i}^{c o n v}\right)=P_{d r o o p, i}-P_{s, i}^{c o n v}=0,
$$

where $P_{d r o o p, i}$ is determined from Fig. 4(a) as follows [26]:

$$
\begin{array}{lc}
K_{\text {max }, i}\left(V_{\text {max }, i}-V_{d, i}\right)+K_{i}\left(V_{\text {high }, i}^{*}-V_{\text {max }, i}\right)+P_{d, i}^{*} \\
& \text { if } V_{d, i} \geq V_{\text {max }, i} ; \\
K_{i}\left(V_{\text {high }, i}^{*}-V_{d, i}\right)+P_{d, i}^{*} & \text { if } V_{h i g h, i}^{*} \leq V_{d, i} \leq V_{\text {max }, i} ; \\
P_{d, i}^{*} & \text { if } V_{\text {low }, i}^{*} \leq V_{d, i} \leq V_{h i g h, i}^{*} ; \\
K_{i}\left(V_{l o w, i}^{*}-V_{d, i}\right)+P_{d, i}^{*} & \text { if } V_{\text {min }, i} \leq V_{d, i} \leq V_{l o w, i}^{*} ; \\
K_{\text {max }, i}\left(V_{\text {min }, i}-V_{d, i}\right)+K_{i}\left(V_{l o w, i}^{*}-V_{\text {min }, i}\right)+P_{d, i}^{*} \\
& \text { if } V_{d, i} \leq V_{\text {min }, i} .
\end{array}
$$

\section{F. VSC Converter Limits}

For control design and stability analysis, it is important to take into account the capability constraints of each VSC converter. These constraints are normally converted into equivalent constraints of voltage and power at the ac terminal in order to be easily embedded in power flow algorithms. In this section, the converter constrains are formulated using the notation for $\mathrm{VSC}_{1}$, but similar expressions applies for $\mathrm{VSC}_{2}$.

1) The RMS converter current $I_{c 1, i}$ is limited by an upper bound $I_{c, i}^{\max }$ to protect switching devices from thermal overheating [22], [23]:

$$
\begin{gathered}
I_{c 1, i} \leq I_{c, i}^{\max } \Longleftrightarrow \\
S_{s, i}^{c o n v} \leq\left|V_{s, i}^{2} \frac{1}{\bar{Z}_{f 1, i}^{*}+\bar{Z}_{T 1, i}^{*}}+\bar{V}_{s, i} \bar{I}_{c, i}^{\max *} \frac{\bar{Z}_{f 1, i}}{\bar{Z}_{f 1, i}^{*}+\bar{Z}_{T 1, i}^{*}}\right|
\end{gathered}
$$

If the VSC output filter does not include the capacitive element (as in the modular multilevel converter technology), (13) simplifies to:

$$
S_{s, i}^{c o n v} \leq I_{c, i}^{\max } V_{s, i}
$$

2) The rms converter voltage $V_{c 1, i}$ is also limited by the voltage $V_{d c, i}$ across the dc-link capacitor to avoid overmodulation [22], [29]:

$$
\begin{gathered}
V_{c 1, i} \leq k_{m} V_{d c, i} \Longleftrightarrow \\
\left(P_{s, i}^{c o n v}-V_{s, i}^{2} G_{1, i}\right)^{2}+\left(Q_{s, i}^{c o n v}+V_{s, i}^{2} B_{1, i}\right)^{2} \leq\left(\frac{k_{m} V_{s, i} V_{d c}}{Z_{1, i}}\right)^{2}
\end{gathered}
$$

where $\left(G_{1, i}+j B_{1, i}\right)=1 / \bar{Z}_{1, i}=1 /\left(\bar{Z}_{T 1, i}+\bar{Z}_{c 1, i}\right)$, assuming the shunt capacitor is omitted, while the value of the coefficient $k_{m}$ depends on the modulation technique.

3) The reactive power absorbed by the converter is also limited with respect to its rated apparent power $S_{\text {rated }}$ :

$$
Q_{s, i}^{c o n v} \geq-k_{Q} S_{\text {rated }},
$$

where the coefficient $k_{Q}$ is project-specific [29], [30].

\section{Algorithm for Solving Power Flow in} Multi-Frequency HVAC AND HVdC POWER Systems

The purpose of this section is to propose an algorithm for solving power flow in general multi-frequency power systems. Power balance equations (1), (3), (7), (8), (10), and (11) are solved using the Newton-Raphson method. These equations can be combined as follows:

$$
\begin{aligned}
g(X) & =g\left(\left[\theta_{s}, V_{s}, \theta_{l}, V_{l}, V_{d}, P_{s}^{c o n v}, P_{l}^{c o n v}, P_{d}^{c o n v}\right]\right) \\
& =\left[g_{s}^{P}, g_{s}^{Q}, g_{l}^{P}, g_{l}^{Q}, g_{d}^{P}, g_{c l}^{P}, g_{c d}^{P}, g_{d r o o p}^{P}\right]=0 .
\end{aligned}
$$


Existing unified power flow algorithms usually consist of two loops. The inner loop solves for the power flow using the Newton-Raphson method, while the outer loop checks the limits of generators and converters that operate in voltagecontrolled mode [19], [20], [26]. However, if one of the limits is violated, the inner loop has to start over, which results in additional iterations. Therefore, this paper proposes a singleloop algorithm in which the limits are checked and immediate modifications are made (as necessary) in each iteration to reduce the number of iterations and total running time. Although extra effort is needed for the limit-checking process, it is still substantially less compared to the computational effort required for the additional iterations in the existing algorithms. The flow chart of the proposed single-loop algorithm is shown in Fig. 5.

\section{A. Initialize}

The algorithm uses a "flat-start" initial condition for all bus voltages and phase angles. The unknown active power $P_{s}^{c o n v}$ and $P_{l}^{c o n v}$ of BTB converters between HVac grid $s$ and LF-HVac grid $l$ are set to zero. The unknown reactive power $Q_{s}^{c o n v}$ and $Q_{l}^{c o n v}$ of the converters operate in voltagecontrolled mode is also set to zero. If a PQ bus in the HVac grid is connected to one of these converters, this bus is switched to a PV bus.

\section{B. Update Converter Active Power}

The active power $\boldsymbol{P}_{\boldsymbol{s}}^{c o n v}$ of the converters between HVac grid $s$ and $\mathrm{HVdc}$ grid $d$ are updated using the $V-P$ droop characteristic shown in Fig. 4 and the updated dc voltage $V_{\boldsymbol{d c}}$.

\section{Calculate Converter Losses}

To calculate the mismatches $\Delta \boldsymbol{g}_{c l}^{P}$ and $\Delta \boldsymbol{g}_{c d}^{P}$ of active power balance in equations (7) and (10), converter losses are calculated in each iteration using (5) and (6).

\section{Update Variable Vector using Newton-Raphson method}

The set of non-linear equations in (17) is simultaneously solved using the Newton-Raphson method. The mismatch $\Delta g(X)$ of power flow equation $g(X)=0$ and the Jacobian $J_{g}(X)$ are calculated by applying vectorization instead of "for" loops to reduce the running time. The updated direction $\Delta \boldsymbol{X}$ at the $k^{t h}$ iteration is determined by solving the set of linear equations (18) using LU factorization.

\section{E. Update Dependent Variables}

The reactive power generated/absorbed by the generators and converters that operate in voltage-controlled mode is updated u sing the new values of $\boldsymbol{X}$. With the power notation shown in Fig. 3, the power generated/absorbed by a generator is updated as follows:

$$
\begin{aligned}
& Q_{s, i}^{g e n(k+1)}=Q_{s, i}{ }^{(k)}+Q_{s, i}^{\text {load }}{ }^{(k)}+Q_{s, i}^{\text {conv }(k)}, \forall i \in \mathcal{G}_{s} . \\
& Q_{l, i}^{g e n(k+1)}=Q_{l, i}{ }^{(k)}-Q_{l, i}^{\text {conv }{ }^{(k)}}, \forall i \in \mathcal{G}_{l} .
\end{aligned}
$$

where $Q_{s, i}{ }^{(k)}$ and $Q_{l, i}{ }^{(k)}$ are calculated using (2). At buses where the voltages are controlled by the reactive power from VSC converters, the unknown reactive power $Q_{s, i}^{c o n v}$ and $Q_{l, i}^{c o n v}$ are updated as follows:

$$
\begin{aligned}
& Q_{s, i}^{\operatorname{conv}(k+1)}=-Q_{s, i}{ }^{(k)}-Q_{s, i}^{\text {load }}{ }^{(k)}, \forall i \in \mathcal{V}_{s} \\
& Q_{l, i}^{\text {conv }}{ }^{(k+1)}=Q_{l, i}{ }^{(k)}, \forall i \in \mathcal{V}_{l}
\end{aligned}
$$

\begin{tabular}{|c|c|c|c|c|c|c|c|c|c|c|c|}
\hline$\frac{\partial \boldsymbol{g}_{s}^{P}}{\partial \boldsymbol{\theta}_{s}}$ & $\frac{\partial \boldsymbol{g}_{s}^{P}}{\partial \boldsymbol{V}_{s}}$ & $\mathbf{0}$ & $\mathbf{0}$ & 0 & $\frac{\partial \boldsymbol{g}_{s}^{P}}{\partial \boldsymbol{P}_{s}^{\text {conv }}}$ & $\mathbf{0}$ & 0 & & $\Delta \boldsymbol{\theta}_{s}$ & & $\Delta \boldsymbol{g}_{s}^{P}$ \\
\hline$\frac{\partial \boldsymbol{g}_{s}^{Q}}{\partial \boldsymbol{\theta}_{s}}$ & $\frac{\partial \boldsymbol{g}_{s}^{Q}}{\partial \boldsymbol{V}_{s}}$ & 0 & 0 & $\mathbf{0}$ & 0 & 0 & $\mathbf{0}$ & & $\Delta \boldsymbol{V}_{s}$ & & $\Delta \boldsymbol{g}_{s}^{Q}$ \\
\hline $\mathbf{0}$ & $\mathbf{0}$ & $\frac{\partial \boldsymbol{g}_{l}^{P}}{\partial \boldsymbol{\theta}_{l}}$ & $\frac{\partial \boldsymbol{g}_{l}^{P}}{\partial \boldsymbol{V}_{l}}$ & $\mathbf{0}$ & $\mathbf{0}$ & $\frac{\partial \boldsymbol{g}_{l}^{P}}{\partial \boldsymbol{P}_{l}^{\text {conv }}}$ & $\mathbf{0}$ & & $\Delta \boldsymbol{\theta}_{l}$ & & $\Delta \boldsymbol{g}_{l}^{P}$ \\
\hline 0 & 0 & $\frac{\partial \boldsymbol{g}_{l}^{Q}}{\partial \boldsymbol{\theta}_{l}}$ & $\frac{\partial \boldsymbol{g}_{l}^{Q}}{\partial \boldsymbol{V}_{l}}$ & 0 & $\mathbf{0}$ & 0 & 0 & $x$ & $\Delta V_{l}$ & $=-$ & $\Delta \boldsymbol{g}_{l}^{Q}$ \\
\hline 0 & $\mathbf{0}$ & 0 & $\mathbf{0}$ & $\frac{\partial \boldsymbol{g}_{d}^{P}}{\partial \boldsymbol{V}_{d}}$ & 0 & 0 & $\frac{\partial \boldsymbol{g}_{d}^{P}}{\partial \boldsymbol{P}_{d}^{\text {conv }}}$ & n & $\Delta \boldsymbol{V}_{d}$ & 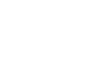 & $\Delta \boldsymbol{g}_{d}^{P}$ \\
\hline $\mathbf{0}$ & $\frac{\partial \boldsymbol{g}_{c l}^{P}}{\partial \boldsymbol{V}_{s}}$ & $\mathbf{0}$ & $\frac{\partial \boldsymbol{g}_{c l}^{P}}{\partial \boldsymbol{V}_{l}}$ & $\mathbf{0}$ & $\frac{\partial \boldsymbol{g}_{c l}^{P}}{\partial \boldsymbol{P}_{s}^{\text {conv }}}$ & $\frac{\partial \boldsymbol{g}_{c l}^{P}}{\partial \boldsymbol{P}_{l}^{\text {conv }}}$ & 0 & & $\Delta \boldsymbol{P}_{s}^{c o n v}$ & & $\Delta \boldsymbol{g}_{c l}^{P}$ \\
\hline $\mathbf{0}$ & $\frac{\partial \boldsymbol{g}_{c d}^{P}}{\partial \boldsymbol{V}_{s}}$ & $\mathbf{0}$ & $\mathbf{0}$ & $\mathbf{0}$ & $\frac{\partial \boldsymbol{g}_{c d}^{P}}{\partial \boldsymbol{P}_{s}^{\text {conv }}}$ & 0 & $\frac{\partial \boldsymbol{g}_{c d}^{P}}{\partial \boldsymbol{P}_{d}^{\text {conv }}}$ & & $\Delta \boldsymbol{P}_{l}^{\text {conv }}$ & & $\Delta \boldsymbol{g}_{c d}^{P}$ \\
\hline 0 & $\mathbf{0}$ & $\mathbf{0}$ & $\mathbf{0}$ & $\frac{\partial \boldsymbol{g}_{d r \text { oop }}^{P}}{\partial \boldsymbol{V}_{d}}$ & $\frac{\partial \boldsymbol{g}_{\text {droop }}^{P}}{\partial \boldsymbol{P}_{s}^{\text {conv }}}$ & $\mathbf{0}$ & 0 & & $\Delta \boldsymbol{P}_{d}^{c o n v}$ & & {$\left[\Delta \boldsymbol{g}_{\text {droop }}^{P}\right\rfloor$} \\
\hline
\end{tabular}

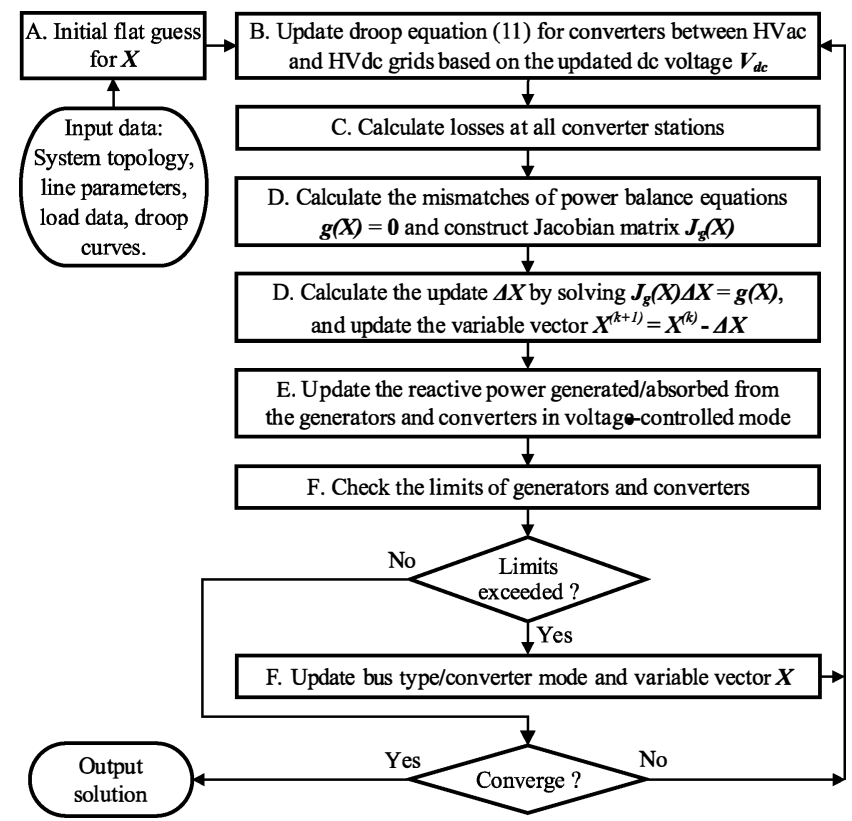

Fig. 5. Flow chart of the proposed single-loop power-flow algorithm for multi-frequency HVac and HVdc systems. 


\section{F. Check Generator and Converter Limits}

One of the convergence criteria is that all generators and converters are operated within their limits. If a generator at a PV bus violates its reactive power limit, that bus is changed to a PQ bus. If a converter operating in voltage-controlled mode violates its limits, as described in (13)-(16), this converter is switched to PQ mode. In both cases, the reactive power is set at the corresponding upper/lower boundary, and variable vector $\boldsymbol{X}$ has additional voltage magnitude components. If the limits of the generator or the converter are satisfied in a successive iteration, the bus is switched back to a PV bus while its voltage magnitude is removed from the variable vector.

This limit-checking step must be done within each iteration in order for the algorithm to converge to the correct solution as well as to reduce the number of iterations. However, since the update $\Delta X$ in the first iterations is usually large, the generator and converter limits might be violated although the final solution does not cause these violations. As discussed above, such violations result in additional iterations. To expedite the running time, the limit-checking process is thus only activated after a first few iterations, which is set to 2 in this paper.

\section{VAlidation of POWER Flow SOlUtion in MULTI-FREQUENCY HVAC AND HVDC POWER SYSTEMS}

This section focuses on the validation of the power flow model and formulation derived in Sections II and III. The analytical solution obtained by implementing the algorithm described in Section IV in Python is compared with the steady-state results from the PSCAD/EMTDC time-domain simulation. The current and voltage controllers for converters in the simulation model are based on [15] and [16].

\section{A. System Description}

The multi-frequency power system shown in Fig. 6, which is modified from the IEEE 14-bus test system [31], is chosen to be studied. Two long transmission lines carrying the highest amounts of power in the original system are operated at $10 \mathrm{~Hz}$ instead of $60 \mathrm{~Hz}$. The transmission line between Bus 1 and Bus 2 in the original $60-\mathrm{Hz}$ HVac grid is replaced by a monopolar HVdc line. To illustrate the bulk power transfer capability of the multi-frequency system, loads are scaled up to between 3 and 5 times their initial values, while the transformer primary (\#1) and secondary (\#2) 60-Hz HVac voltages are set to 500 $\mathrm{kV}$ and $230 \mathrm{kV}$, respectively. The LF-HVac and HVdc grids are operated at $500 \mathrm{kV}$ and $320 \mathrm{kV}$, respectively.

The modified HVac grid consists of 13 buses, including one slack bus, nine PQ buses, and three PV buses. In the LFHVac grid, two BTB converters are located at Bus 14 and Bus 15, and they are connected to Bus 1 and Bus 4 in the HVac grid, respectively. The converter at Bus 16 is omitted to illustrate an application of power generation at low ac frequency. This means that the generator at Bus 16, which is a PV bus, generates electricity directly at $10 \mathrm{~Hz}$. In the $\mathrm{HVdc}$ grid, two VSC converters are needed at Bus 17 and Bus 18, and they are connected to Bus 1 and Bus 2 in the HVac grid, respectively.

In the LF-HVac system with centralized control strategy, Bus 14 is the slack bus of the LF-HVac grid, and the voltage of this bus is controlled at a value of 1.02 pu by the $\mathrm{VSC}_{2}$ side of the converter $A$ between Bus 1 and Bus 14. The angle of the voltage at Bus 14 is set to zero. The active and reactive power injected/withdrawn from the LF-HVac grid is unknown, as discussed in Section II and shown in Table II. At the $\mathrm{VSC}_{1}$ side of the converter, only the reactive power is given, while its active power, accounting for losses in the LF-HVac grid and in the converter station, is unknown. The $\mathrm{VSC}_{1}$ and $\mathrm{VSC}_{2}$ sides of the converter at Bus 15 shown in Fig. 6 are operated in $\mathrm{PQ}$ and $\mathrm{QV}_{\mathrm{dc}}$ modes, respectively. Therefore, the active and reactive power injected/withdrawn from the HVac grid and the reactive power injected/withdrawn from the LF-HViac grid are given.

In the HVdc system shown in Fig. 6, both centralized and distributed control strategies are implemented for converter $C$

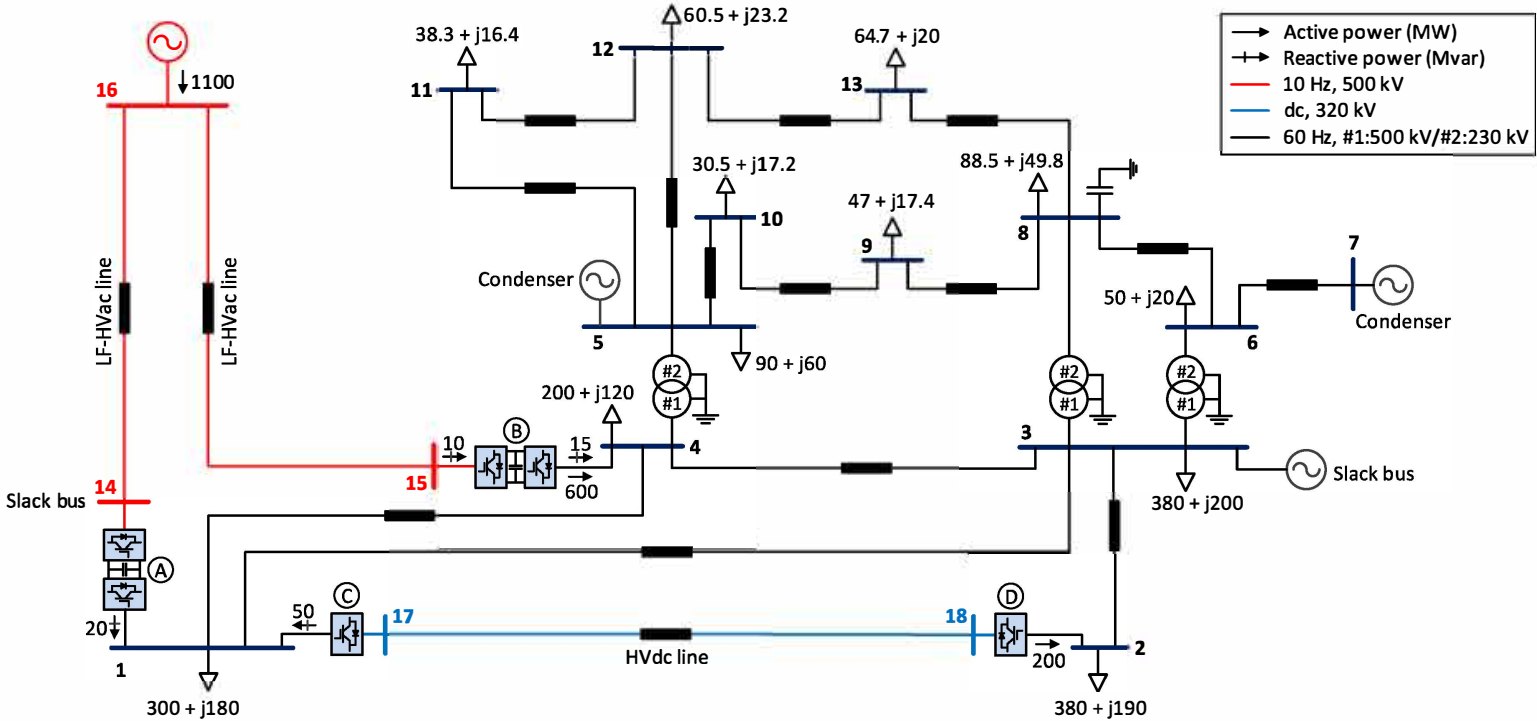

Fig. 6. The multi-frequency power system used to validate the proposed power flow algorithm. It consists of $60-\mathrm{Hz} \mathrm{HVac}$, LF-HVac, and $\mathrm{HVdc}$ lines interconnected by converters. Adapted from [31]. 
TABBLE II

SCHEDULED DATA OF THE CONVERTERS.

\begin{tabular}{|c|c|c|c|c|c|c|c|}
\hline \multicolumn{8}{|c|}{ BTB converters between the HVac and LF-HVac grids } \\
\hline \multirow{2}{*}{ 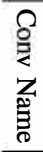 } & \multirow[t]{2}{*}{$\begin{array}{c}\text { From } \\
\text { Bus }\end{array}$} & \multirow[t]{2}{*}{$\begin{array}{l}\text { To } \\
\text { Bus }\end{array}$} & Mode & \multicolumn{2}{|c|}{$\begin{array}{l}\text { Power into } \\
\text { HVac Grid }\end{array}$} & \multicolumn{2}{|c|}{$\begin{array}{l}\text { Power out of } \\
\text { LF-HVac Grid }\end{array}$} \\
\hline & & & $\mathrm{VSC}_{1} \quad \mathrm{VSC}_{2}$ & $\begin{array}{c}P \\
\text { (MW) }\end{array}$ & $\begin{array}{c}Q \\
\text { (Mvar) }\end{array}$ & $\begin{array}{c}P \\
(\mathrm{MW})\end{array}$ & $\begin{array}{c}Q \\
\text { (Mvar) }\end{array}$ \\
\hline$A$ & 1 & 14 & $\mathrm{QV}_{\mathrm{dc}}$ & - & 20.00 & - & - \\
\hline$B$ & 4 & 15 & $\mathrm{QV}_{\mathrm{dc}}$ & 600.00 & 15 & - & 10.00 \\
\hline
\end{tabular}

Converters between the HVac and HVdc grids in centralized control

\begin{tabular}{|c|c|c|c|c|c|c|}
\hline \multirow{2}{*}{$\begin{array}{l}\varrho \\
\wp \\
z \\
z\end{array}$} & \multirow[t]{2}{*}{$\begin{array}{c}\text { From } \\
\text { Bus }\end{array}$} & \multirow[t]{2}{*}{$\begin{array}{l}\text { To } \\
\text { Bus }\end{array}$} & \multirow[t]{2}{*}{ Mode } & \multicolumn{2}{|c|}{$\begin{array}{l}\text { Power into } \\
\text { HVac grid }\end{array}$} & \multirow{2}{*}{$\begin{array}{c}\text { Power out of } \\
\text { HVdc Grid }\end{array}$} \\
\hline & & & & $\begin{array}{c}P \\
(\mathrm{MW})\end{array}$ & $\begin{array}{c}Q \\
\text { (Mvar) }\end{array}$ & \\
\hline$C$ & 1 & 17 & $Q$ & & 50.00 & - \\
\hline$D$ & 2 & 18 & PV & 200.0 & - & - \\
\hline
\end{tabular}

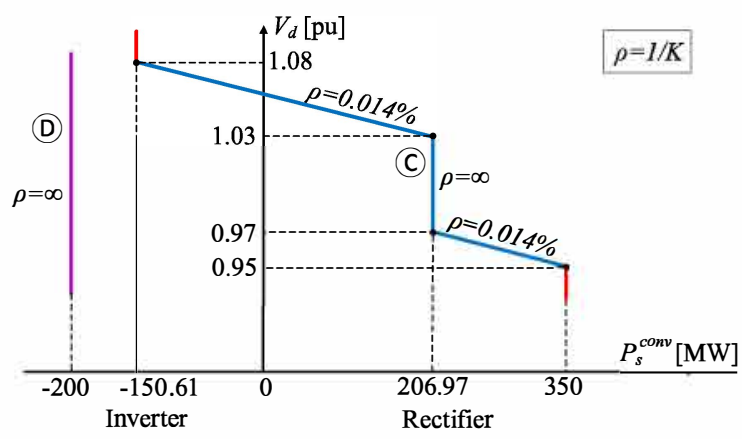

Fig. 7. The droop characteristics of converters $C$ and $D$.

between Bus 1 and Bus 17 and converter $D$ between Bus 2 and Bus 18. For the centralized control, converter $C$ is the slack converter. The HVdc side of this converter controls the $\mathrm{dc}$ voltage level at Bus 17 at a chosen value of $1.02 \mathrm{pu}$. The active power at both sides of this converter are unknown, as shown in Table II. For converter $D$, the injected active power into the HVac grid is given while the injected reactive power varies to keep the voltage at Bus 2 constant at $1.04 \mathrm{pu}$.

For the distributed control, different droop characteristics are assigned for converters $C$ and $D$. While converter $C$ is operated in the $V-P$ droop control with dead bands and voltage limits, converter $D$ is operated in constant active power mode. The operating characteristic of these converters are shown in Fig. 7. To facilitate the verification of the solutions using centralized and distributed controls, all of the reference values and limits of voltage and power as well as droop coefficients shown in Fig. 4(a) are intentionally chosen based on the power flow results determined by the centralized control strategy.

Due to the high load and voltage levels in the modified system, new practical data of tower geometries and conductors from [32]-[34] is chosen, as shown in Table III. The transmission lines in the LF-HVac grid, primary side of the HVac grid, and secondary side of the HVac grid are identical in terms of tower geometry as well as conductor's material, size, and length. Since the accuracy of the transmission line parameters significantly influences the power flow solution, the line model must take into account the effect of the operating frequency on its parameters. Therefore, the frequency-dependent (phase)
TABLE III

TOWER AND CONDUCTOR DATA.

\begin{tabular}{c|c|c|c|c}
\hline Grid & $\begin{array}{c}\text { Voltage } \\
\text { Level }\end{array}$ & $\begin{array}{c}\text { Tower } \\
\text { Configuration }\end{array}$ & $\begin{array}{c}\text { Conductor } \\
\text { Code }\end{array}$ & $\begin{array}{c}\text { Conductor } \\
\text { Length }\end{array}$ \\
\hline HVac - Pri & $500 \mathrm{kV} \mathrm{ac}$ & $5 \mathrm{~L} 10$ & Blue Bird & $150 \mathrm{~km}$ \\
HVac - Sec & $230 \mathrm{kV} \mathrm{ac}$ & $3 \mathrm{H} 5$ & Tern & $80 \mathrm{~km}$ \\
\hline LF-HVac & $500 \mathrm{kV} \mathrm{ac}$ & $5 \mathrm{~L} 10$ & Blue Bird & $300 \mathrm{~km}$ \\
\hline HVdc & $320 \mathrm{kV} \mathrm{dc}$ & N1 & ACSR-AL3 & $300 \mathrm{~km}$ \\
\hline
\end{tabular}

TABLE IV

Bus Voltage SOlution OF THE HVAC AND LF-HVAC GRIDS.

\begin{tabular}{|c|c|c|c|c|c|}
\hline \multicolumn{6}{|c|}{ HVac Grid } \\
\hline \multirow[b]{2}{*}{ Bus } & \multirow[b]{2}{*}{ Type } & \multicolumn{2}{|c|}{ PF Solution } & \multicolumn{2}{|c|}{ PSCAD/EMTDC } \\
\hline & & $\begin{array}{l}|V| \\
(\mathrm{pu})\end{array}$ & $\begin{array}{c}\theta \\
(\operatorname{deg})\end{array}$ & $\begin{array}{l}|V| \\
(\mathrm{pu})\end{array}$ & $\begin{array}{c}\theta \\
(\operatorname{deg})\end{array}$ \\
\hline 1 & PQ & 1.0486 & 0.61 & 1.049 & 0.60 \\
\hline 2 & $\mathrm{PV} \rightarrow \mathrm{PQ}$ & 1.0333 & -2.18 & 1.033 & -2.17 \\
\hline 3 & slack & 1.0400 & 0.00 & 1.040 & 0.00 \\
\hline 4 & $\mathrm{PQ}$ & 1.0424 & 1.48 & 1.042 & 1.48 \\
\hline 5 & PV & 1.0100 & -25.65 & 1.010 & -25.65 \\
\hline 6 & PQ & 1.0157 & -21.05 & 1.016 & -21.05 \\
\hline 7 & PV & 1.0100 & -21.01 & 1.010 & -21.01 \\
\hline 8 & $\mathrm{PQ}$ & 1.0178 & -24.74 & 1.018 & -24.75 \\
\hline 9 & $\mathrm{PQ}$ & 1.0151 & -26.18 & 1.015 & -26.18 \\
\hline 10 & $\mathrm{PQ}$ & 1.0130 & -26.34 & 1.013 & -26.34 \\
\hline 11 & PQ & 1.0112 & -26.84 & 1.011 & -26.84 \\
\hline 12 & PQ & 1.0119 & -26.97 & 1.012 & -26.97 \\
\hline 13 & PQ & 1.0131 & -26.73 & 1.013 & -26.72 \\
\hline \multicolumn{6}{|c|}{ LF-HVac Grid } \\
\hline \multirow[b]{2}{*}{ Bus } & \multirow[b]{2}{*}{ Type } & \multicolumn{2}{|c|}{ PF Solution } & \multicolumn{2}{|c|}{ PSCAD/EMTDC } \\
\hline & & $\begin{array}{l}|V| \\
(\mathrm{pu})\end{array}$ & $\begin{array}{c}\theta \\
(\mathrm{deg})\end{array}$ & $\begin{array}{l}|V| \\
(\mathrm{pu})\end{array}$ & $\begin{array}{c}\theta \\
(\mathrm{deg})\end{array}$ \\
\hline 14 & slack & 1.0100 & 0.00 & 1.010 & 0.00 \\
\hline 15 & $\mathrm{PQ}$ & 1.0107 & -0.51 & 1.011 & -0.51 \\
\hline 16 & PV & 1.0200 & 2.07 & 1.020 & 2.07 \\
\hline \multicolumn{6}{|c|}{ HVdc Grid } \\
\hline \multirow[b]{2}{*}{ Bus } & \multirow[b]{2}{*}{ Type } & \multicolumn{2}{|c|}{ PF Solution } & \multicolumn{2}{|c|}{ PSCAD/EMTDC } \\
\hline & & \multicolumn{2}{|c|}{$\begin{array}{l}|V| \\
(\mathrm{pu})\end{array}$} & \multicolumn{2}{|c|}{$\begin{array}{l}|V| \\
(\mathrm{pu})\end{array}$} \\
\hline 17 & & \multicolumn{2}{|c|}{1.0200} & \multicolumn{2}{|c|}{1.020} \\
\hline 18 & & \multicolumn{2}{|c|}{0.9856} & \multicolumn{2}{|c|}{0.986} \\
\hline
\end{tabular}

model in PSCAD/EMTDC is employed to generate the distributed parameters of transmission lines based on the data from Table III [35]. These distributed values are then used to obtain the lumped parameters of the equivalent- $\pi$ model. To achieve more accurate results, the shunt conductance $G^{\prime}$ representing the dielectric loss between conductors is included.

In order to directly compare the analytical solution with the the time-domain PSCAD/EMTDC simulation results, the conductor loss in the transmission lines is taken into account, while the Joule and switching losses in the VSCs are excluded. This means that converter resistances $R_{c 1}$ and $R_{c 2}$ in (6) as well as quadratic coefficients in (6) are set to zero.

\section{B. Numerical and Time-Domain Simulation Results}

The analytical solution and the simulation results are summarized in Table IV and Table V, while Table VI shows the complete converter solution. The red and blue numbers indicate the solution of the power flow; these values are unknown prior to solving the power flow. The analytical solutions with 
TABLE V

POWER GENERATED/ABSORBED BY GENERATORS.

\begin{tabular}{c|c|c|cc|cc}
\hline \multirow{2}{*}{ Grid } & \multirow{2}{*}{ Bus } & \multirow{2}{*}{ Type } & \multicolumn{2}{|c|}{ PF Solution } & \multicolumn{2}{c}{ PSCAD/EMTDC } \\
\cline { 4 - 7 } & & $\begin{array}{c}P_{\text {gen }} \\
(\mathrm{MW})\end{array}$ & $\begin{array}{c}Q_{\text {gen }} \\
(\mathrm{Mvar})\end{array}$ & $\begin{array}{c}P_{\text {gen }} \\
(\mathrm{MW})\end{array}$ & $\begin{array}{c}Q_{\text {gen }} \\
(\text { Mvar })\end{array}$ \\
\hline \multirow{3}{*}{ HVac } & 3 & slack & 652.55 & -10.72 & 652.61 & -10.93 \\
& 5 & PV & 0.00 & 2.47 & 0.00 & 2.46 \\
& 7 & PV & 0.00 & -23.77 & 0.00 & -23.77 \\
\hline LF-HVac & 16 & PV & 1100.00 & -9.84 & 1101.3 & -9.98 \\
\hline
\end{tabular}

TABLE VI

CONVERTER SOLUTION.

\begin{tabular}{|c|c|c|c|c|c|c|c|c|}
\hline \multicolumn{5}{|c|}{ PF Solution } & \multicolumn{4}{|c|}{ PSCAD/EMTDC } \\
\hline \multicolumn{9}{|c|}{ BTB converters between the HVac and LF-HVac grids } \\
\hline \multirow{2}{*}{ 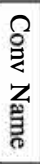 } & \multicolumn{2}{|c|}{$\begin{array}{l}\text { Power into } \\
\text { HVac Grid }\end{array}$} & \multicolumn{2}{|c|}{$\begin{array}{c}\text { Power out of } \\
\text { LF-HVac Grid }\end{array}$} & \multicolumn{2}{|c|}{$\begin{array}{l}\text { Power into } \\
\text { HVac Grid }\end{array}$} & \multicolumn{2}{|c|}{$\begin{array}{c}\text { Power out of } \\
\text { LF-HVac Grid }\end{array}$} \\
\hline & $\begin{array}{c}P \\
(\mathrm{MW})\end{array}$ & $\begin{array}{c}Q \\
\text { (Mvar) }\end{array}$ & $\begin{array}{c}P \\
\text { (MW) }\end{array}$ & $\begin{array}{c}Q \\
\text { (Mvar) }\end{array}$ & $\begin{array}{c}P \\
(\mathrm{MW})\end{array}$ & $\begin{array}{c}Q \\
(\mathrm{Mvar})\end{array}$ & $\begin{array}{c}P \\
(\mathrm{MW})\end{array}$ & $\begin{array}{c}Q \\
\text { (Mvar) }\end{array}$ \\
\hline$A$ & 488.90 & 20.00 & 488.90 & 47.19 & 488.80 & 20.03 & 489.10 & 47.11 \\
\hline$B$ & 600.00 & 15.00 & 600.00 & 10.00 & 599.90 & 15.03 & 600.30 & 9.98 \\
\hline \multicolumn{9}{|c|}{ Converters between the HVac and HVdc grids } \\
\hline 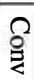 & \multicolumn{2}{|c|}{$\begin{array}{l}\text { Power into } \\
\text { HVac Grid }\end{array}$} & \multicolumn{2}{|c|}{$\begin{array}{c}\text { Power out of } \\
\text { HVdc Grid }\end{array}$} & \multicolumn{2}{|c|}{$\begin{array}{l}\text { Power into } \\
\text { HVac Grid }\end{array}$} & \multicolumn{2}{|c|}{$\begin{array}{c}\text { Power out of } \\
\text { HVdc Grid }\end{array}$} \\
\hline $\begin{array}{l}\text { Z } \\
\text { : } \\
\text { के }\end{array}$ & $\begin{array}{c}P \\
(\mathrm{MW})\end{array}$ & $\begin{array}{c}Q \\
\text { (Mvar) }\end{array}$ & $\begin{array}{c}P \\
\text { (MW) }\end{array}$ & & $\begin{array}{c}P \\
(\mathrm{MW})\end{array}$ & $\begin{array}{c}Q \\
(\mathrm{Mvar})\end{array}$ & $\begin{array}{c}P \\
(\mathrm{MW})\end{array}$ & \\
\hline$C$ & -206.97 & 50.00 & -206.97 & & -207.00 & 50.07 & -206.50 & \\
\hline$D$ & 200.00 & 84.21 & 200.00 & & 199.90 & 84.22 & 200.80 & \\
\hline
\end{tabular}

both centralized and distributed controls for the HVdc grid are completely identical. These solutions are also found to closely match the steady-state time-domain simulation results (with centralized for the HVdc grid), which verifies both the power flow model and the formulation proposed in Section II and III, as well as the algorithm described in Section IV. At Bus 2 of the HVac grid, after the first limit-checking step, the power injected into the HVac grid is found to exceed the current limit, as shown in (13), of converter $D$. Therefore, this bus switches from a PV bus to a PQ bus, and the operating mode of the associated converter changes from $\mathrm{PV}$ to $\mathrm{PQ}$.

\section{Convergence and Scalability}

With the droop control strategy implemented in HVdc grid $d$, a proper modification of the Jacobian matrix might be needed if all converters operate in dead-band or constant power modes to avoid singularity [26]. However, with similar power balance equations and centralized operation with a slack bus between HVac and LF-HVac grids, the introduction of the latter in a multi-frequency power system does not result in any extra convergence issues.

The power flow algorithm is implemented on an Intel Core i7-3770 processor with 10GB RAM. The tolerance is set to $10^{-6} \mathrm{pu}$. With the centralized and distributed control strategies implemented for HVdc grid $d$, the algorithm described in Section IV converges in 7 iterations after 0.028 seconds and 8 iterations after 0.032 seconds, respectively. In contrast to the sequential approach used in [21], the proposed algorithm does not get any convergence issues due to the limit violation of converter $D$ and type-switching of Bus 2. On the other hand, as expected, the simulation using PSCAD/EMTDC takes 12 hours to reach the steady state because the converters are represented in detailed time-domain switching models.

The proposed formulation and algorithm are also verified to solve power flow in a larger power system. This second case is modified from the IEEE 57-bus system [31] in a similar way as the system in Fig. 6. The HVac, LF-HVac, and HVdc grids consist of 57, 6, and 3 buses, respectively. While the five BTB converters that connect the HVac and LF-HVac grids are operated using the centralized control, a distributed control with linear droop characteristics is implemented for the three converters between the HVac and HVdc grids. The algorithm converges after 8 iterations in 0.042 seconds. Such rapid convergences with a stable and small number of iterations in the two studied systems indicate that the proposed formulation and algorithm can be incorporated in other realtime applications such as optimal power flow.

\section{CONCLUSION}

This paper presents operating modes and a power flow model for BTB converters in multi-frequency power systems. The power flow formulation of multi-frequency power system is derived from the power balance equations of each grid. The power flow solution is obtained by an efficient singleloop algorithm based on the unified approach. The algorithm is applicable regardless of the number of converters or ac/dc grids, operating frequencies of ac grids, system topology, and centralized or distributed control strategies for the HVdc grids. For the case study, the mismatches between the analytical solutions are the simulation results are quite small; the largest mismatch between voltage amplitude and line flow are $0.4 \%$ and $0.23 \%$, respectively. The solution converges rapidly, which makes it applicable for solving power flow or other real-time applications in large power systems.

\section{APPENDIX}

The first derivatives of power balance equations with respect to voltages' magnitudes and angles in the HVac and LF-HVac grids are given in [36]. Other non-zero entries in the Jacobian matrix in (18) are determined as follows:

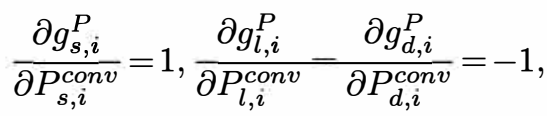

$$
\begin{aligned}
& \frac{\partial g_{d, i}^{P}}{\partial V_{d, k}}=\left\{\begin{array}{l}
k_{t y p e}\left(\sum_{p \in \mathcal{N}_{d}} V_{d, p} Y_{d, i p}+V_{d, i} Y_{d, i i}\right), \text { if } i=k \\
k_{t y p e} V_{d, i} Y_{d, i k}, \text { if } i \neq k,
\end{array}\right. \\
& \frac{\partial g_{c l, i}^{P}}{\partial V_{s, i}}=\frac{\partial g_{c d, i}^{P}}{\partial V_{s, i}}=-2\left(R_{1, i}+a_{2}\right) \frac{\left|S_{s, i}^{c o n v}\right|^{2}}{V_{s, i}^{3}}-a_{1} \frac{\left|S_{s, i}^{c o n v}\right|}{V_{s, i}^{2}}, \\
& \frac{\partial g_{c l, i}^{P}}{\partial V_{l, i}}=-2\left(R_{2, i}+a_{2}\right) \frac{\left|S_{l, i}^{c o n v}\right|^{2}}{V_{l, i}^{3}}-a_{1} \frac{\left|S_{l, i}^{c o n v}\right|}{V_{l, i}^{2}}, \\
& \frac{\partial g_{c l, i}^{P}}{\partial P_{s, i}^{c o n v}}-\frac{\partial g_{c d, i}^{P}}{\partial P_{s, i}^{c o n v}}=-1+2\left(R_{1, i}+a_{2}\right) \frac{P_{s, i}^{c o n v}}{V_{s, i}^{2}}+a_{1} \frac{P_{s, i}^{c o n v}}{V_{s, i}\left|S_{s, i}^{c o n v}\right|}, \\
& \frac{\partial g_{c l, i}^{P}}{\partial P_{l, i}^{c o n v}}=1+2\left(R_{2, i}+a_{2}\right) \frac{P_{l, i}^{c o n v}}{V_{l, i}^{2}}+a_{1} \frac{P_{l, i}^{c o n v}}{V_{l, i}\left|S_{l, i}^{c o n v}\right|},
\end{aligned}
$$




$$
\frac{\partial g_{c d, i}^{P}}{\partial P_{d, i}^{c o n v}}=1+2\left(R_{1, i}+a_{2}\right) \frac{P_{s, i}^{c o n v}}{V_{s, i}^{2}}+a_{1} \frac{P_{s, i}^{c o n v}}{V_{s, i}\left|S_{s, i}^{c o n v}\right|},
$$

where:

$$
\begin{aligned}
R_{1, i} & =R_{T 1, i}+R_{c 1, i}, R_{2, i}=R_{T 2, i}+R_{c 2, i} \\
\left|S_{s, i}^{c o n v}\right| & =\sqrt{\left(P_{s, i}^{c o n v}\right)^{2}+\left(Q_{s, i}^{c o n v}\right)^{2}} \\
\left|S_{l, i}^{\text {conv }}\right| & =\sqrt{\left(P_{l, i}^{c o n v}\right)^{2}+\left(Q_{l, i}^{\text {conv }}\right)^{2}}
\end{aligned}
$$

Note that the element $\partial g_{c l, i}^{P} / \partial P_{s, i}^{c o n v}$ in (25) is written only for the power balance at the converter station connected to the slack bus in LF-HVac grid $l$. In addition, the elements (24)-(27) corresponding to the power balance equations $\boldsymbol{g}_{c l}^{P}$ and $\boldsymbol{g}_{c d}^{\boldsymbol{P}}$ in converter stations are derived by ignoring the shunt capacitor values. This approach only approximates the updated direction $\Delta X$. Upon convergence, the solution $\boldsymbol{X}$ is the solution of the exact model described in Section III.

\section{REFERENCES}

[1] K. Meah and S. Ula, "Comparative evaluation of HVDC and HVAC transmission systems," in Power Engineering Society General Meeting, 2007. IEEE, June 2007, pp. 1-5.

[2] P. Bresesti, W. L. Kling, R. L. Hendriks, and R. Vailati, "HVDC connection of offshore wind farms to the transmission system," IEEE Transactions on Energy Conversion, vol. 22, no. 1, March 2007.

[3] D. Jovcic, D. van Hertem, K. Linden, J. P. Taisne, and W. Grieshaber, "Feasibility of DC transmission networks," in Innovative Smart Grid Technologies (ISGT Europe), 2011 2nd IEEE PES International Conference and Exhibition on, Dec 2011, pp. 1-8.

[4] D. Jovcic and K. Ahmed, High Voltage Direct Curent Transmisison: Converters, Systems, and DC Grids. Wiley, 2015.

[5] C. M. Franck, "HVDC circuit breakers: A review identifying future research needs," IEEE Transactions on Power Delivery, vol. 26, no. 2, pp. 998-1007, April 2011.

[6] T. Funaki and K. Matsuura, "Feasibility of the low frequency AC transmission," in Power Engineering Society Winter Meeting, 2000. IEEE, vol. 4, 2000, pp. 2693-2698 vol.4.

[7] W. Fischer, R. Braun, and I. Erlich, "Low frequency high voltage offshore grid for transmission of renewable power," in 2012 3rd IEEE PES Innovative Smart Grid Technologies Europe (ISGT Europe), Oct 2012, pp. 1-6.

[8] "Low frequency transmission," PSERC Publication, Tech. Rep., 2012.

[9] Y. Cho, G. J. Cokkinides, and A. P. Meliopoulos, "LFAC-transmission systems for remote wind farms using a three-phase, six-pulse cycloconverter" in 2012 IEEE Power Electronics and Machines in Wind Applications, July 2012, pp. 1-7.

[10] T. Ngo, M. Lwin, and S. Santoso, "Steady-state analysis and performance of low frequency ac transmission lines," IEEE Transactions on Power Systems, vol. 31, no. 5, pp. 3873-3880, Sept 2016.

[11] T. Ngo, Q. Nguyen, and S. Santoso, "Voltage stability of low frequency ac transmission systems," in 2016 IEEE/PES Transmission and Distribution Conference and Exposition (T\&D), May 2016, pp. 1-5.

[12] D. Rosewater, Q. Nguyen, and S. Santoso, "Optimal field voltage and energy storage control for stabilizing synchronous generators on flexible ac transmission systems," in 2018 IEEE/PES Transmission and Distribution Conference and Exposition (T D), April 2018, pp. 1-9.

[13] T. Russell, "ScottishPower Renewables Investigates low frequency transmission for EA3," https://www.4coff shore.com/windfarms/ scottishpower-renewables-investigates-low-frequency-transmission-forea3-nid4661.html, Tech. Rep., 2016.

[14] I. Erlich, F. Shewarega, H. Wrede, and W. Fischer, "Low frequency ac for offshore wind power transmission - prospects and challenges," in 11 th IET International Conference on AC and DC Power Transmission, Feb 2015, pp. 1-7.

[15] R. Teodorescu, M. Liserre, and P.. Rodrguez, Grid converters for photovoltaic and wind power systems. John Wiley, Ltd, 2011.

[16] J. Qin and M. Saeedifard, "Predictive control of a modular multilevel converter for a back-to-back HVDC system," IEEE Transactions on Power Delivery, vol. 27, no. 3, pp. 1538-1547, July 2012.
[17] A. Calle-Prado, S. Alepuz, J. Bordonau, P. Cortes, and J. Rodriguez, "Predictive control of a back-to-back NPC converter-based wind power system," IEEE Transactions on Industrial Electronics, vol. 63, no. 7, pp. 4615-4627, July 2016.

[18] Q. Nguyen, T. Ngo, and S. Santoso, "Power flow solution for multifrequency AC power systems," in 2016 IEEE/PES Transmission and Distribution Conference and Exposition, May 2016, pp. 1-5.

[19] M. Baradar and M. Ghandhari, "A multi-option unified power flow approach for hybrid AC/DC grids incorporating multi-terminal VSCHVDC," IEEE Transactions on Power Systems, vol. 28, no. 3, Aug 2013.

20] X.-P. Zhang, "Multiterminal voltage-sourced converter-based HVDC models for power flow analysis," IEEE Transactions on Power Systems, vol. 19, no. 4, pp. 1877-1884, Nov 2004.

[21] J. Beerten, S. Cole, and R. Belmans, "Generalized steady-state VSC MTDC model for sequential AC/DC power flow algorithms," IEEE Transactions on Power Systems, vol. 27, no. 2, pp. 821-829, May 2012.

[22] J. Beerten, R. Belmans, and S. Cole, "A sequential AC/DC power flow algorithm for networks containing multi-terminal VSC HVDC systems," in IEEE PES General Meeting, July 2010, pp. 1-7.

[23] M. Z. Kamh and R. Iravani, "Steady-state model and power-flow analysis of single-phase electronically coupled distributed energy resources," IEEE Transactions on Power Delivery, vol. 27, no. 1, pp. 131-139, Jan 2012.

[24] - - "Unbalanced model and power-flow analysis of microgrids and active distribution systems," IEEE Transactions on Power Delivery, vol. 25, no. 4, pp. 2851-2858, Oct 2010.

[25] S. Li, T. A. Haskew, and L. Xu, "Control of HVDC light system using conventional and direct current vector control approaches," IEEE Transactions on Power Electronics, vol. 25, no. 12, Dec 2010.

[26] W. Wang and M. Barnes, "Power flow algorithms for multi-terminal VSC-HVDC with droop control," IEEE Transactions on Power Systems, vol. 29, no. 4, pp. 1721-1730, July 2014.

[27] T. M. Haileselassie and K. Uhlen, "Impact of DC line voltage drops on power flow of MTDC using droop control," IEEE Transactions on Power Systems, vol. 27, no. 3, pp. 1441-1449, Aug 2012.

[28] J. Beerten, D. V. Hertem, and R. Belmans, "VSC MTDC systems with a distributed DC voltage control - a power flow approach," in 2011 IEEE Trondheim PowerTech, June 2011, pp. 1-6.

[29] W. Feng, L. A. Tuan, L. B. Tjernberg, A. Mannikoff, and A. Bergman, "A new approach for benefit evaluation of multiterminal VSC HVDC using a proposed mixed AC-DC optimal power flow," IEEE Transactions on Power Delivery, vol. 29, no. 1, pp. 432-443, Feb 2014.

[30] ABB, "It is time to connect with offshore wind supplement," https://library.e.abb.com/public/lbad1970cd0766eec1257b28005757df/ Pow0038\%20R6\%20LR.pdf, Tech. Rep., 2010.

[31] Literature-based power flow test cases. [Online]. Available: http //icseg.iti.illinois.edu/power-cases/

[32] EPRI, AC Transmission line reference book - $200 \mathrm{kV}$ and above. 3rd edition, Electric Power Research Institute, Palo Alto, California, 2005.

[33] —-, HVDC Transmission Line Reference Book. Electric Power Research Institute, Palo Alto, California, 1993.

[34] "Overhead electrical conductors - calculation methods for stranded bare conductors," International Electrotechnical Commission (IEC), Tech. Rep., 1995.

[35] EMTDC transient analysis for PSCAD power system simulation [Online]. Available: https:///hvdc.ca/uploads/ck/files/reference_material/ EMTDC_User_Guide_v4_3_1.pdf

[36] J. Glover, M. Sarma, and T. Overbye, Power System Analysis and Design. Cengage Learning, 2011.

Quan Nguyen ( $\left.\mathrm{S}^{\prime} 15\right)$ is a $\mathrm{PhD}$ student at the University of Texas at Austin. His research interests are power system modeling and optimization, renewable energy integration, power quality, and power electronics.

Grazia Todeschini (SM'14) is Senior Lecturer at Swansea University, UK. Her research interests include power quality, renewable energy integration, and power system analysis.

Surya Santoso (F'15) is Professor of Electrical and Computer Engineering at the University of Texas at Austin. His research interests include power quality, power systems, and renewable energy integration. 